\title{
WHAT PREDICTS CHEATING AMONG STUDENTS? A CROSS CULTURAL COMPARISON BETWEEN ONLINE AND FACE-TO-FACE COURSES
}

\author{
Yovav Eshet ${ }^{1}$, Yehuda Peled ${ }^{2}$, Keren Grinautski ${ }^{3}$ and Casimir Barczyk ${ }^{4}$ \\ ${ }^{I}$ PhD, Interdisciplinary Department, Zefat Academic College, 11 Jerusalem St, POB: 160, Zefat, 1320611, Israel \\ ${ }^{2}$ PhD, Information Studies, Western Galilee College, POB: 2125, Akko 2412100, Israel \\ ${ }^{3}$ MBA, School of Management, University of Haifa, Haifa 3190501, Israel \\ ${ }^{4}$ PhD, School of Management, Purdue University Calumet, Hammond IN 46323, United States
}

\begin{abstract}
Many researchers have dwelled on the phenomenon of academic dishonesty (AD) or unethical behaviors within the academic environment. While this phenomenon can be explained by various factors, the current study investigates and presents a new structural model for determinants of $\mathrm{AD}$. The predictors of $\mathrm{AD}$ that were found in the context of traditional and distance-learning courses in higher education are types of motivation, students' attitudes, personality traits, and cultural backgrounds (presented by country according to Hofstede's cultural dimensions theory). This study was conducted using a survey method of 2,357 students studying in six different academic institutes. Using structural equation modeling (SEM) the results indicate that the surveyed students tend to engage less in $\mathrm{AD}$ in online courses than in face-to-face courses. This notion is contrary to the traditional views and the research literature, therefore, having important practical implications for educators, institution and researchers dealing with course design development and institutional policy concerning pedagogical uses of digital technology.
\end{abstract}

\section{KEYWORDS}

Academic Dishonesty, Distance Learning, Online Courses, Motivation

\section{INTRODUCTION}

One of the largest and fastest growing segments of education is online learning (Kincey, Farmer, Wiltsher, McKenzie \& Mbiza, 2019). A study by Higher Education Reports Babson Survey Research Group in 2018 revealed a growth at public institutions grew by 7.3 percent, and private non-profit institutions grew by 7.1 percent in United States (Seaman, Allen, and Seaman, 2018). Convenience and flexibility are what students' value when deciding to enroll in online courses. (Toufaily, Zalan, \& Lee, 2018). Copious research suggests that online and classroom-based instruction result in equivalent outcomes for student in most higher education settings. (Shea \& Bidjerano, 2018).

Academic dishonesty (AD) is a long-standing, culturally dependent, universal phenomenon relate to what is right or wrong (Martin, Rao, and Sloan, 2011; Peled and Khaldi, 2013). It is an important issue in education (Yang, Huang, and Chen, 2013) that continues to be a pervasive problem in the academic arena (Arnold, 2016), as most students have engaged in academic misconduct at some point of their careers (Stuber-McEwen, Wiseley, and Hoggatt, 2009). According to Jones (2011), the 92\% of surveyed students report that they had cheated at least once or knew someone who had.

The scholarly research ascertains that online cheating is prevalent over traditional forms (Chuang, 2015; Fontaine, 2012; Kennedy, Nowak, Raghuraman, Thomas, and Davis, 2000). For example, Kennedy et al. (2000) surveyed students in many different academic areas and showed that $64 \%$ of 69 faculty members, and $57 \%$ out of 172 students, felt that cheating was easier in online exams. The belief that cheating is easier in online exams is also indicated in the research of King, Guyette and Piotrowski (2009) where 73.6\% of 121 undergraduate business students agreed that it was easier to cheat online. 
Many reports show that students admit that they are more likely to cheat in online courses. Chapman and colleagues (Chapman, Davis, Toy, and Wright, 2004) found that $24 \%$ of 824 business students indicated that they had cheated on an electronic exam, and that $42 \%$ of them claimed that if given the opportunity, they would cheat in electronic exams. Students also indicated that electronic testing was one of the several important, situational determinants related to the probability of cheating. Lanier (2006) found that $41.1 \%$ of the students surveyed admitted to cheating in online courses. Watson and Sottile (2010) surveyed undergraduate and graduate students across many academic fields and found that students were significantly more likely to obtain answers from other students during an online test or quiz.

To test traditional beliefs that online cheating prevails over traditional forms of cheating, and focusing on students cheating propensity, we surveyed 2,357 undergraduate students, enrolled in online courses, and compared to face to face courses. We have controlled the following predictor variables - personality traits, motivation, attitude toward academic dishonesty and cultural differences (by country).

The scholarly research has addressed various factors explaining the concept of AD. One such factor relates to the quick development in the field of Instructional Technology, which has resulted in the proliferation of online courses. Since these courses lessen the personal contact between students and faculty members, students are provided with a greater opportunity to engage in academic misconduct (Peterson, 2019; Walker, 2010). Thus, online courses, in contrast to traditional classroom courses, may contribute to students engaging in higher levels of dishonesty. The reason for this is that they feel more "distant" or separated from others (Kelley and Bonner, 2005).

Other studies have determined the availability and the accessibility of digital information as factors affecting AD (Cole et al, 2018). Some claim that this has made plagiarism more common due to the ease of copying and pasting the work of others while claiming it is one's own (Lehman and DuFrene, 2011; Walker, 2010). The students' lack of perception and understanding of institutional policy regarding academic dishonesty (Ewing, Anast, and Roehling, 2016; Şendağ, Duran, and Fraser, 2012) may be another element encouraging misbehavior.

The scholarly research has also shown that: societal factors, achievement goal approaches to motivation, internal and external motivation, external pressures to meet high standards of performance or deadlines, the desire to excel, fear of failure, or the lack of personal integrity, may explain dishonest behavior in the academic setting (Griebeler, 2019; Imran and Ayobami, 2011; Maeda, 2019; McCabe, Trevino, and Butterfield, 2001; Ramlan et al, 2019; Van Yperen, Hamstra, and Van der Klauw, 2011).

Additional explanations are the individual's desire to attain social acceptance, to keep up with peers, to further advance in their careers, to please others, or to protect their livelihood (Imran and Ayobami, 2011; McCabe et al., 2001; Van Yperen et al., 2011).

Several studies showed that the type of course (face-to-face vs. online) (Eshet, Grinautski, Peled, and Barczyk, 2014; Spaulding, 2011) and the different personality traits (Giluk and Postlethwaite, 2015; Wilks, Cruz, and Sousa, 2016) determine the intensity of AD. Despite the extensive academic literature, one of the most fundamental questions in this field remains not fully answered: what are the factors that predict students' propensity to engage in AD? This research is expected to provide a substantial contribution to the understanding of unethical behavior in the academic environment. The findings show that academic misconduct can be predicted and explained by the type of course in which students are enrolled, their background characteristics, type of motivation, personality traits, their instructor's attitude towards $\mathrm{AD}$, and their cultural background (presented by country).

\subsection{Hypotheses}

Hypothesis 1. There will be level differences in the various motivational types between students that learn in traditional settings and those that are e-learners, which in turn, result in differences in the cheating propensity. E-learners will show higher levels of intrinsic motivation and have less propensity to engage in academic misconduct than students in traditional face-to-face settings.

Hypothesis 2. There will be differences in students' levels of Academic dishonesty based on their predominant personality traits.

Hypothesis 3. There will be differences in the level of Academic dishonesty based on faculty members' attitudes towards dishonest behaviors. 
Hypothesis 4. Uncertainty avoidance will have an impact on academic misconduct, thus, Israeli students will report less incidence of Academic dishonesty than their counterparts in the United States do.

The basic research question underlying the four hypotheses detailed above is: which factors affect a students' tendency to engage in academic misconduct?

\section{METHOD}

\subsection{Research Settings and Participants}

The sample consisted of 2,475 students: 841 participants from the two abovementioned USA academic institutions and 1,634 from the four abovementioned colleges in the North of Israel. About two thirds $(69 \%)$ of the participants were women and a third (31\%) were men. Their ages ranged between 17 and 64 $(\mathrm{M}=26.54$ years). A third of the participants (33\%) were freshmen, 35\% sophomores, $16 \%$ juniors, $13 \%$ seniors, and 3\% were graduate students. About a third of the participants in USA (36\%) enrolled to online courses, while $64 \%$ enrolled to face-to-face courses.

A similar distribution can be seen in Israel, $37 \%$ enrolled to online courses, while $63 \%$ enrolled to face-to-face courses. Five percent of the participants were excluded from the analysis because their survey instruments were incomplete (less than $80 \%$ ) or carelessly completed. Missing values were replaced by the variable average. The final data set consisted of 2,357 participants.

\subsection{Survey Instrument}

A five-part survey instrument measured the following variables: $\mathrm{AD}$, motivational orientation, personality traits, attitude measures, and socio-demographic status.

\subsection{Independent Variables}

Motivational orientation - this part of the survey instrument contained 16 items that were compiled from the Academic Self-Regulation Questionnaire (SRQ-A) (Ryan and Connell, 1989). Four types of motivation are examined in the questionnaire: identified regulation, introjected regulation, external regulation, and intrinsic motivation on a four-point Likert scale $(\alpha=0.75)$.

Personality traits - this part of the survey included the TIPI scale developed by Gosling, Rentfrow, and Swann (2003), which consisted of 10 items designed to assess the participants' personality traits. Every trait consisted of two statements $(\alpha=0.63)$.

Attitude measures - this part of the questionnaire was designed to measure the attitudes of lecturers towards AD based on Coalter and colleagues' (2007) survey that included 30 questions on a five-point Likert scale $(\alpha=0.76)$.

Perceived opportunity - this part of the questionnaire was based on the Perceived Opportunity Scale by Bolin (2004) on a five-point Likert scale $(\alpha=0.73)$.

Acting - this part of the questionnaire was based on Shipley's (2009) Academic Dishonesty Survey (Penalty and Self Report items) with Cronbach's alpha of 0.72.

Socio-demographic variables - the questionnaire also contained a series of demographic items that related to the participants' age, gender, grade point average, and type of course enrollment (elective versus required and on-line versus face-to-face).

\subsection{Dependent Variable}

Academic dishonesty - Using the Academic Integrity Inventory, this part of the survey instrument included questions about Likelihood of considering misconduct (Kisamore, Stone, and Jawahar, 2007), based on 5 items with a reliability of $\alpha=0.75$. The engagement in each academically dishonest behavior, is measured using an Academic Dishonesty Scale (Bolin, 2004), based on 10 items, with a reliability of $\alpha=0.91$. 


\subsection{Procedure}

A printed version of the survey instrument was administered in traditional face-to-face courses and an on-line version of the same in the e-learning courses. We used the stratified sampling method. The survey instruments were coded and grouped according to the location of the participants' college or university.

\subsection{Results}

Descriptive statistics and a correlation matrix summarizing the study variables are presented in Table 1 (see Appendix A). All measures of AD (consisting of items related to forms of misconduct, plagiarism, and cheating) and covariates (four types of motivation and most of the socio-demographic variables) were correlated with one another (Table 1).

Table 1. Correlation matrix of the study variables

\begin{tabular}{|c|c|c|c|c|c|c|c|c|c|c|c|c|c|c|c|c|c|c|c|}
\hline \multicolumn{2}{|l|}{ Variables } & 1 & 2 & 3 & 4 & 5 & 6 & 7 & 8 & 9 & 10 & 11 & 12 & 13 & 14 & 15 & 16 & 17 & 18 \\
\hline \multicolumn{2}{|c|}{ 1. Esternal Motiration } & $=$ & & & & & & & & & & & & & & & & & \\
\hline \multicolumn{2}{|c|}{ 3. Identified Regulation } & $.107^{\prime *}$ & $.629^{\circ *}$ & $=$ & & & & & & & & & & & & & & & \\
\hline \multicolumn{2}{|c|}{ 4. Intrinsic Motivation } & $.314^{* \cdots}$ & $.273^{\prime \prime}$ & $.230 \cdots$ & $=$ & & & & & & & & & & & & & & \\
\hline \multicolumn{2}{|c|}{ 6. Agreeableness } & $-.101^{\prime *}$ & $-.060^{\prime \prime}$ & $-.055^{\circ}$ & $.052^{\circ}$ & $-063^{\circ}$ & $==$ & & & & & & & & & & & & \\
\hline \multicolumn{2}{|c|}{ 7. Conscientiousness } & -015 & $.056^{\circ}$ & $.058^{\circ}$ & $.142^{\cdots}$ & $.168^{\prime \prime}$ & $.200 \cdots$ & $=$ & & & & & & & & & & & \\
\hline \multicolumn{2}{|c|}{ 8. Emotional Stability } & $-076^{\prime \prime}$ & $-.078^{\prime \prime}$ & -013 & .072" & $.149 \cdots$ & $.278 " \cdots$ & $.339 \cdots$ & $=$ & & & & & & & & & & \\
\hline \multicolumn{2}{|c|}{ 11. Perceived Opportunity } & -015 & $.190 \%$ & $.224^{\cdots}$ & $.084 \cdots$ & -.020 & $.112 \cdots$ & $.069 *$ & .041 & $.127^{\prime}$ & $.550 \cdots$ & $=$ & & & & & & & \\
\hline \multicolumn{2}{|c|}{ 12. Taking Action } & $-.115^{\prime \prime}$ & $.064^{*}$ & $.161^{\prime \prime}$ & .035 & -029 & $.046^{\circ}$ & .016 & -.006 & $.053^{\circ}$ & $.252 \ldots$ & $.161^{\prime *}$ & $==$ & & & & & & \\
\hline \multicolumn{2}{|c|}{ 13. Course Type } & $47.50^{-*}$ & $89.61^{\prime \prime}$ & $216.70^{\cdots \cdot-}$ & $229.76^{\circ}$ & $32.61^{\circ}$ & $23.78^{\circ}$ & $38.07^{\prime \prime}$ & $30.48^{*}$ & $22.80^{\circ}$ & $191.33^{\prime *}$ & 201.84" & 50.08 & $=$ & & & & & \\
\hline \multicolumn{2}{|l|}{ 14. Age } & $-130^{\circ-\cdots}$ & $-.073^{*}$ & -.030 & $.156^{\prime \prime}$ & $.084^{\cdots}$ & $.171^{\cdots}$ & $.063^{*}$ & $.140^{\cdots}$ & $.079 "$ & .027 & $.053^{\circ}$ & .027 & $141.98^{*}$ & $=$ & & & & \\
\hline \multicolumn{2}{|c|}{ 15. Gender } & 24.17 & 35.41 & 12.87 & $49.99^{\cdots \cdot}$ & 16.13 & $55.41^{*}$ & $41.27^{\circ}$ & $24.05^{*}$ & 18.53 & 127.47 & $87.49^{\circ}$ & 47.57 & .025 & $10296^{*-}$ & $=$ & & & \\
\hline \multirow[t]{2}{*}{$\mathrm{Us}_{\mathrm{A}}$} & S.D. & 0.65 & 0.61 & 0.62 & 0.74 & 1.52 & 1.25 & 1.22 & 1.37 & 1.14 & 0.49 & 0.65 & 0.72 & 0.48 & 7.46 & 0.48 & 12.98 & 0.47 & 0.65 \\
\hline & $\mathrm{s}$ & 799 & 800 & 800 & 798 & 797 & 798 & 796 & 797 & 796 & 798 & 783 & 795 & 801 & 750 & 783 & 698 & 764 & 799 \\
\hline \multirow{3}{*}{ Israel } & $\mathrm{s}$ & 2.64 & 2.64 & 281 & 2.85 & 4.69 & 5.08 & 5.88 & 5.13 & 5.19 & 3.24 & 3.11 & 2.87 & 0.63 & 27.24 & 0.28 & 83.75 & 0.77 & 1.95 \\
\hline & S.D. & 0.64 & 0.64 & 0.94 & 0.73 & 1.35 & 1.11 & 1.12 & 1.24 & 1.11 & 0.43 & 0.63 & 0.67 & 0.48 & 7.82 & 0.45 & 7.22 & 0.42 & 0.63 \\
\hline & $\mathrm{s}$ & 1.548 & 1.549 & 1.552 & 1.548 & 1.130 & 1.129 & 1.131 & 1.129 & 1.130 & 1.098 & 1.075 & 1.086 & 1.556 & 1.424 & 1.451 & 997 & 1.556 & 1.476 \\
\hline \multicolumn{2}{|c|}{ Independent $T$ test } & $-2.75^{* \prime}$ & $17.24^{*}$ & $21.14^{\cdots \prime}$ & $10.69^{\cdots \cdots}$ & $4.65^{* *}$ & 4.96 & $5.31^{\cdots *}$ & $5.86{ }^{\prime \prime}$ & $4.63^{\cdots \cdots}$ & 24.04 & $17.28^{\circ *}$ & $16.14^{\cdots \cdots}$ & $=$ & $-5.88^{\cdots *}$ & $=$ & $19.65^{* \cdots}$ & $=$ & 0.33 \\
\hline \multicolumn{2}{|c|}{ Cohen's deffect size } & 0.09 & 0.61 & 0.74 & 0.38 & 0.17 & 0.18 & 0.19 & 0.21 & 0.16 & 0.85 & 0.60 & 0.56 & $=$ & 0.21 & $=$ & 0.57 & $=$ & $=$ \\
\hline
\end{tabular}

T-test analyses between countries (USA and Israel) were conducted with the study variables (Table 1). The results indicate that there is a significant difference between the USA and Israel in external motivation $\left[\mathrm{t}_{(2355)}=-2.75, \mathrm{p}=.006\right]$, intrinsic motivation $\left[\mathrm{t}_{(2355)}=-10.69, \mathrm{p}=.000\right]$, extraversion $\left[\mathrm{t}_{(2355)}=-4.65, \mathrm{p}=.000\right]$, agreeableness $\left[\mathrm{t}_{(2355)}=-4.96, \mathrm{p}=.000\right]$, conscientiousness $\left[\mathrm{t}_{(2355)}=-5.31, \mathrm{p}=.000\right]$, emotional stability $\left[\mathrm{t}_{(2355)}=-5.86, \mathrm{p}=.000\right]$, age $\left[\mathrm{t}_{(2355)}=-5.88, \mathrm{p}=.000\right]$, and grade point average $\left[\mathrm{t}_{(2355)}=-19.65, \mathrm{p}=.000\right]$, with higher levels found in Israel compared to the USA. Also, a significant difference between USA and Israel was found in introjected regulation $\left[\mathrm{t}_{(2355)}=17.24, \mathrm{p}=.000\right]$, identified regulation $\left[\mathrm{t}_{(2355)}=21.14, \mathrm{p}=.000\right]$, openness to experience $\left[\mathrm{t}_{(2355)}=4.63, \mathrm{p}=.000\right]$, attitude measures $\left[\mathrm{t}_{(2355)}=24.04, \mathrm{p}=.000\right]$, perceived opportunity $\left[\mathrm{t}_{(2355)}=17.28, \mathrm{p}=.000\right]$, and taking action $\left[\mathrm{t}_{(2355)}=16.14, \mathrm{p}=.000\right]$, with higher levels found in the USA compared to Israel.

\subsection{Plan of Analysis}

Full information maximum likelihood estimates were computed by means of the Analysis of Moment Structures (AMOS) program (Arbuckle and Wothke, 1999). Structural models linking types of motivation, culture (presented by country), course type (face-to-face vs. online), age, gender, grade point average, type of course enrollment (required vs. elective), and AD were tested, the results of which are summarized in Figure 1. The model was examined for goodness of fit using $\chi^{2}$, comparative fit index (CFI), and root mean square 
error of approximation (RMSEA) fit indices. CFI values above 0.90 and 0.95 indicate adequate and good model fit, respectively, and RMSEA values below 0.08 and 0.05 indicate adequate and good model fit, respectively (Browne and Cudeck, 1992; Hu andBentler, 1999; Kline, 1998). CFI = .991, RMSEA = 0.045). The structural model is diagrammed in Figure 1.

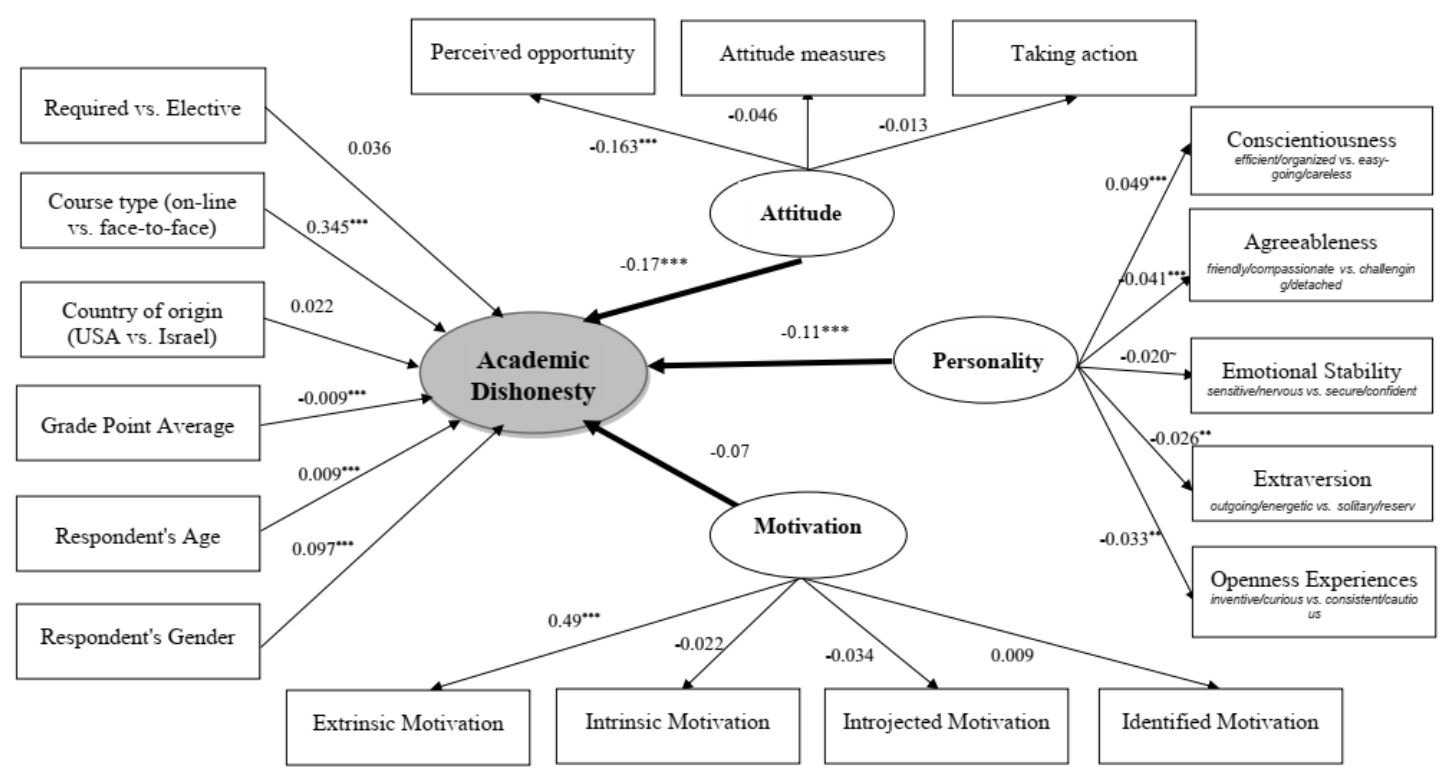

Figure 1. Structural model for determinants of academic dishonesty with standardized Coefficients

The results of the $\mathrm{AD}$ analysis indicate that the variance in students' propensity to engage in $\mathrm{AD}$ is explained by the research variables: students' motivational orientation, students' personality traits, attitudes of lecturers towards academic dishonesty, students' perception of the opportunities to cheat, students' attitude towards punishment for acts of academic dishonesty, type of course (on-line vs. face-to-face), gender, age, grade point average, and type of course enrollment (elective vs. required). As shown in Figure 1, course type is the variable that has the largest impact on AD. Surveyed students in on-line courses tend to engage less in academic misconduct than their counterparts in face-to-face courses.

Other variables that were found to have a significant influence on the dependent variable are divided. Some have a positive impact and others have a negative one. More specifically, the personality trait of extraversion and extrinsic motivation increase the students' tendency to cheat, while this tendency increases with age. By contrast, the other Big Five personality traits (conscientiousness, emotional stability, agreeableness, and openness to experience), as well as studying in academic institutions that consider acts of academic misconduct as very serious offences, and act upon them with severity, lessen the inclination to engage in dishonest behaviors.

\section{CONCLUSION}

This research suggests that our understanding of the factors that influence AD needs to be adjusted. The essence of this study is to investigate which variables (type of course to which students are enrolled, background characteristics, type of motivation, personality traits, instructor's attitude towards AD, and cultural background [presented by country]) help predict and determine academic misconduct.

We empirically tested four hypotheses, of which three of them were confirmed by the survey's data; the fourth is proved wrong by evidence. We have found that: (1) e-learners exhibited less propensity to engage in AD if compared to their counterparts in face-to-face courses; (2) personality traits explained the students' willingness to engage in dishonest behaviors; (3) faculty members' attitudes toward AD explained to which extent were students willing to engage in dishonest behaviors; (4) both Israeli and USA students had the same level when engaging in $\mathrm{AD}$ conduct. Although when asked if they would not report misbehavior, only 
$29 \%$ of the American students answered yes, $57 \%$ of their Israeli colleagues would not report on a peer's misconduct. This may be due to both, the different manners people interpret whistle blowing on a peer misbehavior, and their ethical sensitivity, on the one hand, and on the positive or negative outcome (McIntosh et al., 2017), on the other hand.

Although, some researchers have asserted that distance learning environments provide and promote opportunities for AD compared to traditional learning environments (e.g., Cole, Shelley, and Swartz, 2012, pp. 1-19; Shachar and Neumann, 2010). Others reject this claim altogether (Black, Greaser, and Dawson, 2008). The findings of this study show that students tend to cheat more in face-to-face classroom settings. Furthermore, course type was found to have the greatest impact on $\mathrm{AD}$ among all other examined factors.

These results may be interpreted according to Yang et al. (2013) and Geddes (2011), who found that students who participate in online courses have a higher motivation to learn or are able to learn independently, which could substantially reduce their desire to cheat compared to students participating in traditional face-to-face classroom settings. Another possible explanation for these results is that more intrinsically motivated students self-select online as opposed to traditional classroom courses.

On-line instruction is thought to facilitate increasing levels of intrinsic motivation. Thus, it is not surprising that e-learning students manifest significantly higher levels of intrinsic motivation and significantly lower levels of extrinsic motivation than traditional classroom students do.

Conscientious students have less need to cheat, since they tend to be better prepared academically and can resist cheating. They may be achievement-oriented, but at the same time, responsible, honest, and able to regulate their behavior. Similarly, emotional stability can also help students avoid unethical academic behaviors, since students that are high on this trait have a sense of security, which allows them to be less influenced by stressful conditions. In addition, a significant negative correlation between the personality trait of agreeableness and $\mathrm{AD}$ indicates that the more students are cooperative with others, the less likely they are to be academically dishonest. Agreeableness is associated with the ability to create good relationships and conform to group norms. By contrast, highly extroverted students tend to be talkative, aggressive, verbal, sociable, bold, assertive, unrestrained, confident, attention-seeking, and domineering (De Raad, 2000). Thus, the positive influence of the personality traits of extraversion and emotional stability as predictors

for $\mathrm{AD}$ can be interpreted by the notion that unlike extraversion, these traits enable students to withhold the tendency to cheat.

In line with the research literature we hold that understanding the factors influencing $\mathrm{AD}$ is a crucial issue. Moreover, it has important implications for both, institutional policies, and course design. Nonetheless, contrary to traditional views ascribing online cheating a prevalence over face to face courses our findings show that the antecedents of $\mathrm{AD}$ need to be revised.

Consequently, we conclude that online courses are not a predominant factor in the prediction of misbehavior. Next, we show that the principal variables predicting the tendency to cheat are related to personality traits, faculty's attitudes, and institutional policies. The study's practical implications are related to course design and institutional policy.

\section{REFERENCES}

Arbuckle, J., and Wothke, W., 1999. AMOS 4.0 User's Reference Guide. Small Waters Corporation, Chicago, USA.

Arnold, I.J., 2016. Cheating at online formative tests: Does it pay off? The Internet and Higher Education, Vol. 29, pp. 98-106.

Black, E.W., Greaser, J., and Dawson, K., 2008. Academic dishonesty in traditional and online Classrooms: Does the "media equation" hold true? Journal of Asynchronous Learning Networks, Vol, 12, No. 3-4, pp. 23-30.

Bolin, A., 2004. Self-control, perceived opportunity, and attitudes as predictors of academic dishonesty. Journal of Psychology Interdisciplinary and Applied, Vol. 138, No. 2, pp. 101-114.

Browne, M.W., and Cudeck, R., 1992. Alternative ways of assessing model fit. Sociological Methods and Research, Vol. 21, pp. 230-258.

Chapman, K. et al, 2004. Academic integrity in the business school environment: I'll get by with a little help from my friends. Journal of Marketing Education, Vol. 26, No. 3, pp. 236-249.

Chuang, C.Y., 2015. Improving Proctoring by Using Non-Verbal Cues During Remotely Administrated Exams. Arizona State University, USA. 
Coalter, T. et al, 2007. Factors that influence faculty actions: A study on faculty responses to academic dishonesty. International Journal for the Scholarship of Teaching and Learning, Vol. 1, No. 1, pp. 1-19.

Cole, M.T. et al, 2012. Academic Integrity and Student Satisfaction in an Online Environment. Cases on Online Learning Communities and Beyond: Investigations and Applications. IGI Global, Hershey, USA.

Cole, M.T. et al, 2018. In Re Launching a New Vision in Education and e-Learning: Fostering a Culture of Academic Integrity in e-Learning. Smart Education and e-Learning, pp. 151-164.

De Raad, B., 2000. The Big Five Personality Factors: The Psycholexical Approach to Personality. Hogrefe and Huber Publisher.

Eshet, Y. et al, 2014. No more excuses - personality traits and academic dishonesty in online courses. Journal of Statistical Science and Application, Vol. 2, pp. 111-118.

Ewing, H. et al, 2016. Addressing plagiarism in online programmes at a health sciences university: A case study. Assessment and Evaluation in Higher Education, Vol. 41, No. 4, pp. 575-585.

Fontaine, J., 2012. Online classes see cheating go high-tech. The Chronicle of Higher Education, Vol. 58, No. 38, pp. A1-A2.

Geddes, K.A., 2011. Academic dishonesty among gifted and high-achieving students. The Gifted Child Today, Vol. 34, No. 2, pp. 50-56.

Giluk, T.L., and Postlethwaite, B.E., 2015. Big five personality and academic dishonesty: A meta-analytic review. Personality and Individual Differences, Vol. 72, pp. 59-67.

Gosling, S.D. et al, 2003. A very brief measure of the big five personality domains. Journal of Research in Personality, Vol. 37, pp. 504-528.

Griebeler, M.C., 2019. "But everybody's doing it!": A model of peer effects on student cheating. Theory and Decision, Vol. 86, No, 2, pp. 259-281.

Hu, L., and Bentler, P.M., 1999. Cutoff criteria for fit indexes in covariance structure analysis: Conventional criteria versus new alternatives. Structural Equation Modeling, Vol. 6, pp. 1-55.

Imran, A.M., and Ayobami, O.R., 2011. Academic dishonesty among tertiary institution students: An exploration of the societal influences using SEM analysis. International Journal of Education, Vol. 3, No. 2, pp. 1-15.

Jones, D.L., 2011. Academic dishonesty: Are more students cheating? Business Communication Quarterly, Vol. 74, No. 2, pp. 141.

Kelley, K., and Bonner, K., 2005. Distance education and academic dishonesty: Faculty and administrator perception and responses. Journal of Asynchronous Learning Networks, Vol. 9, pp. 43-52.

Kennedy, K. et al, 2000. Academic dishonesty and distance learning: Student and faculty views. College Student Journal, Vol. 34, No. 2, pp. 309-314.

Kincey, S.D., Farmer, E.D., Wiltsher, C.Y., McKenzie, D. \& Mbiza, S.T. 2019, "From Chalkboard to Digital Media: The Evolution of Technology and Its Relationship to Minority Students' Learning Experiences", The Journal of Faculty Development, vol. 33, no. 1, pp. 65-75.

King, C. et al, 2009. Online exams and cheating: An empirical analysis of business students' views. The Journal of Educators Online, Vol. 6, No. 1.

Kisamore, J.L. et al. 2007. Academic integrity: The relationship between individual and situational factors on misconduct contemplations. Journal of Business Ethics, Vol. 75, pp. 381-394.

Kline, R.B., 1998. Principles and Practice of Structural Equation Modeling. Guilford, New York, USA.

Lanier, M.M., 2006. Academic integrity and distance learning. Journal of Criminal Justice Education, Vol. 17, No. 2, pp. 244-261.

Lehman, C.M., and DuFrene, D., 2011. Business Communication (16th ed.). South-Western/Cengage Learning, Mason, $\mathrm{OH}, \mathrm{USA}$.

Martin, D.E. et al, 2011. Ethnicity, acculturation, and plagiarism: A criterion study of unethical academic conduct. Human Organization, Vol. 70, No. 1, pp. 88-96.

Maeda, M., 2019. Exam cheating among Cambodian students: When, how, and why it happens. A Journal of Comparative and International Education.

McCabe, D.L. et al, 2001. Cheating in academic institutions: A decade of research. Ethics and Behavior, Vol. 11, pp. 219-232.

McIntosh, T. et al, 2017. To whistleblow or not to whistleblow: Affective and cognitive differences in reporting peers and Advisors. Science and Engineering Ethics, pp. 1-40.

Peled, Y., and Khaldi, S., 2013. Are discrimination, survival and tradition sufficient argument for academic dishonesty? Discrimination, Survival and Tradition as Argumentation for Academic Dishonesty. Educational Practice and Theory, Vol. 35, No. 1, pp. 41-61. 
Peterson, J., 2019. An Analysis of Academic Dishonesty in Online Classes. Mid-Western Educational Researcher, Vol, 31, No. 1, pp. 24-36.

Ramla, M. et al, 2019. Spiritual intelligence and academic dishonesty: The Malaysian higher education student perspectives. European Journal of Education Studies, Vol. 6, No. 2, pp. 205-222.

Ryan, R.M., and Connell, J.P., 1989. Perceived locus of causality and internalization: Examining reasons for acting in two domains. Journal of Personality and Social Psychology, Vol. 57, pp. 749-761.

Seaman, J.E., Allen, I.E. and Seaman, J., 2018. Grade Increase: Tracking Distance Education in the United States. Babson Survey Research Group.

Şendağ, S. et al, 2012. Surveying the extent of involvement in online academic dishonesty (e-dishonesty) related practices among university students and the rationale students provide: One university's experience. Computers in Human Behavior, Vol. 28, No. 3, pp. 849-860.

Shachar, M., and Neumann, Y., 2010. Twenty years of research on the academic performance differences between traditional and distance learning: Summative meta-analysis and trend examination. MERLOT Journal of Online Learning and Teaching, Vol. 6, No. 2.

Shea, P. \& Bidjerano, T. 2018, "Online Course Enrollment in Community College and Degree Completion: The Tipping Point", International Review of Research in Open and Distance Learning, vol. 19, no. 2

Shipley, L.J., 2009. Academic and professional dishonesty: Student views of cheating in the classroom and on the job. Journalism and Mass Communication Educator, Vol. 64, No. 1, pp. 39-53.

Stuber-McEwen, D. et al, 2009. Point, click, and cheat: Frequency and type of academic dishonesty in the virtual classroom. Online Journal of Distance Learning Administration, Vol. 12, No. 3.

Toufaily, E., Zalan, T. \& Lee, D. 2018, "What do learners value in online education? An emerging market perspective", The e - Journal of Business Education \& Scholarship of Teaching, vol. 12, no. 2, pp. 24-39.

Van Yperen, N.W. et al, 2011. To win, or not to lose, at any cost: The impact of achievement goals on cheating. British Journal of Management. Vol. 22, No. s1, pp. S5-S15.

Walker, J., 2010. Measuring plagiarism: Researching what students do, not what they say they do. Studies in Higher Education, Vol. 35, pp. 41-59.

Watson, G., and Sottile, J., 2010. Cheating in the digital age: Do students cheat more in online courses? Online Journal of Distance Learning Administration, Vol. 12, No. 4.

Wilks, D.C. et al, 2016. Personality traits and plagiarism: An empirical study with Portuguese undergraduate students. Journal of Academic Ethics, Vol. 14, No. 3, pp. 231-241.

Yang, S.C. et al, 2013. An investigation of college students' perceptions of academic dishonesty, reasons for dishonesty, achievement goals, and willingness to report dishonest behavior. Ethics and Behavior, Vol. 23, No. 6, pp. 501-522. 